\title{
Utilisation de la biosynthèse effectuée par des bactéries et des moisissures pour l'enrichissement des fourrages en protéines et vitamines à partir d'hydrates de carbone
}

\author{
par \\ W. BEDNARSKI, J. JAKUBOWSKI, S. POZNANSKI \\ et \\ A. SURAZYNSKI \\ Chaire de la Technologie Laitière \\ de l'Université d'Agriculture à Olsztyn (Pologne) \\ (Chef de la Chaire : Dr habil. S. POZNANSKI, Pr Agr.)
}

\section{I. - INTRODUCTION}

Au cours des dernières années, des communications ont paru dans la littérature mondiale disant qu'en faisant fermenter des produits de céréales par certaines espèces de moisissures, on pouvait obtenir un produit ayant une teneur élevée en protéines et vitamines et se caractérisant par une odeur agréable de noix et une saveur ressemblant à celle de la viande. Dans le Rapport de la Research Station Pretoria [14] mention est faite qu'en résultat de la fermentation de la farine par Rhizopus oligosporus, un produit était obtenu qui pouvait, selon l'avis des Auteurs, compenser le défaut de protéines dans le régime alimentaire des gens dont la nourriture se composait principalement d'hydrates de carbone.

Il ressort des communications de Tatcher [13] que le mycélium de quelques genres de moisissures, telles que Candida, Rhizopus et Fusarium, pouvait être consommé par l'homme.

Des recherches tchécoslovaques [9] ont montré la présence de protéines précieuses dans le mycélium, qu'on avait obtenu comme déchet au cours de la fabrication des antibiotiques, de l'acide citrique et d'autres produits.

En Pologne, Dluzewski [16] a réussi à effectuer la biosynthèse de protéines et de vitamines sur des milieux artificiels : glucose, acides aminés et sels minéraux. 
Au cours de la présente expérimentation, on a essayé d'effectuer la biosynthèse des protéines et de certaines vitamines en utilisant diverses espèces de moisissures et de bactéries, et, en quelques cas, des levures, dans des milieux liquides, ainsi que sur le milieu composé de lactosérum, de pommes de terre étuvées et de sels minéraux, pour transformer les hydrates de carbone d'aliments peu coûteux en fourrage concentré de haute qualité.

\section{II. - EXPERIMENTATION}

\section{1) Utilité du milieu à hydrates de carbone pour le développement du mycélium de moisissures, avec considération particulière de la synthèse des protéines et des vitamines $B_{1}$ et $B$}

Pour l'expérimentation on a utilisé les espèces de moisissures suivantes : Penicillium roqueforti WR-16 du Laboratoire des Cultures pures lactiques à OIsztyn, Oospora lactis - 15 de la Collection des Souches de la Chaire de la Microbiologie technique de l'Université d'agriculture à Olsztyn, Zygorrhynchus spaecies Meelleri LECK-81 de la Chaire de la Microbiologie technique de l'Ecole Polytechnique à Lodz, Rhizopus oligosporus CBS 33962 du Laboratoire Central, Collection des souches à Berne.

Dans la première étape, les moisissures étaient cultivées dans des bouteilles de Roux sur des milieux contenant :

a) lactosérum, déprotéinisé thermiquement,

b) moût de brasserie,

c) solution à 1 p. 100 de dextrine.

Ces milieux étaient additionnés de sels minéraux, à savoir : 0,5 p. $100 / \mathrm{NH}_{4} /{ }_{2} \mathrm{HPO}_{4}-0,5$ p. $100 \mathrm{~K}_{2} \mathrm{HPO}_{\text {s }}$ et 0,05 p. $100 \mathrm{MgSO}_{4} \cdot 7 \mathrm{H}_{2} \mathrm{O}$. Puis l'acidité du milieu était ajustée à $\mathrm{pH} 5$ et la culture désirée était ensemencée avec une culture de moisissure. L'incubation durait $120 \mathrm{~h}$ à $25^{\circ} \mathrm{C}$. Au cours du développement du mycélium des pertes d'extrait sec étaient observées. Le coefficient de rendement était calculé de la diminution de l'extrait sec du milieu après la culture des moisissures, par rapport à la quantité de l'extrait sec avant la culture. Chaque valeur qui caractérisait la teneur du produit obtenu en le composant étudié, était multipliée par le coefficient de perte de l'extrait $\mathrm{sec}$, pour éviter l'erreur due à l'augmentation apparente de ce composant qui résultait du changement d'une partie de l'extrait sec en combinaisons volatiles. Ce coefficient était établi empiriquement et il égalait 0,8 .

Dans des essais témoins et expérimentaux, on a déterminé la teneur en azote total, en protéines précipitables par l'acide trichloracétique - ATA - concentration de 12 p. 100 dans un échantillon -, en substances azotées précipitables par l'acide phosphotungstique APT (8), la teneur en vitamines $B_{1}$ et $B_{2}$, d'après la méthode fluori- 
métrique de Nesterov [10] et la teneur en sucres réducteurs, d'après la méthode de Bertrand.

L'aptitude à synthétiser des protéines et des vitamines de la part des quatre espèces de moisissures utilisées est présentée dans le tableau 1. Dans la biosynthèse des protéines sur le lactosérum, les moisissures $P$. roqueforti et $O$. lactis ont été dominantes. La culture de ces moisissures faisait augmenter la teneur en protéines des échantillons d'essais, jusqu'à 270 et 247 p. 100 , respectivement, en comparaison avec les témoins.

Le moût s'est montré le milieu le plus convenable pour la synthèse des protéines par la plupart des moisissures. $P$. roqueforti y synthétisait 320 p. 100, Z. Meelleri 226 p. 100, R. oligosporus 170 p. 100 et $O$. lactis 178 p. 100 des protéines de plus, en comparaison avec le témoin. Par contre, la solution de dextrine s'est montrée la moins convenable pour la biosynthèse des protéines, tandis que les quantités de vitamines $B_{1}$ et $B_{2}$ y étaient relativement élevées. En considérant les pertes manifestes de l'azote minéral dans les cultures sur les milieux étudiés - en comparaison avec les témoins - et des différences distinctes de teneur en protéines précipitables par APT, on peut constater que les moisissures utilisaient des composés azotés anorganiques pour synthétiser les protéines à poids moléculaires assez élevé. Le but principal de cette expérimentation étant de montrer l'utilité du lactosérum et de l'amidon pour la fabrication de préparations d'amidon et de protéines utilisées comme fourrages, on a étudié à son tour la biosynthèse des protéines et des vitamines par des bactéries et des moisissures sur un milieu composé de lactosérum et de pommes de terre.

\section{2) Biosynthèse des protéines et des vitamines sur milieu de lac- tosérum et de pommes de terre}

Dans cette partie de l'expérimentation, la biosynthèse de protéines procédait en deux étapes. En premier, la biomasse des bactéries était multipliée sur le lactosérum. Puis le même milieu était enrichi en amidon, pour créer des conditions favorables à la continuation de la biosynthèse des protéines et des vitamines par les moisissures étudiées.

\section{a) Préparation du milieu et conditions de la biosynthèse}

Le milieu était préparé à partir de lactosérum provenant de la fabrication des fromages, ou bien du même lactosérum, condensé deux fois et additionné, à 15 p. 100 de son de froment et des microéléments nécessaires : $\mathrm{KH}_{2} \mathrm{PO}_{4} / 0,5 \mathrm{~g} / 1$ et $\mathrm{MgSO}_{4} .7 \mathrm{H}_{2} \mathrm{O} / 0,12 \mathrm{~g} / 1$. Comme source d'azote, on a ajouté $1,25-8,0 \mathrm{~g} / 1$ d'urée, ou bien $0,5 \mathrm{p} .100$ de $\mathrm{NH}_{4} /{ }_{3} \mathrm{PO}_{4} 3 \mathrm{H}_{2} \mathrm{O}$, et, dans la phase finale de l'expérimentation, ces deux composants ensemble, à la dose de 0,5 p. 100 pour chacun. Dans le milieu ainsi préparé, la biomasse bactérienne était multipliée jusqu'au moment où la teneur en lactose atteignait 0,4 à 0,5 p. 100 . 
TABLEAU 1

Aptitude de quatre espèces de moisissures à synthétiser des protéines et des vitamines sur le lactosérum, le moût et la dextrine (comparé avec des témoins)

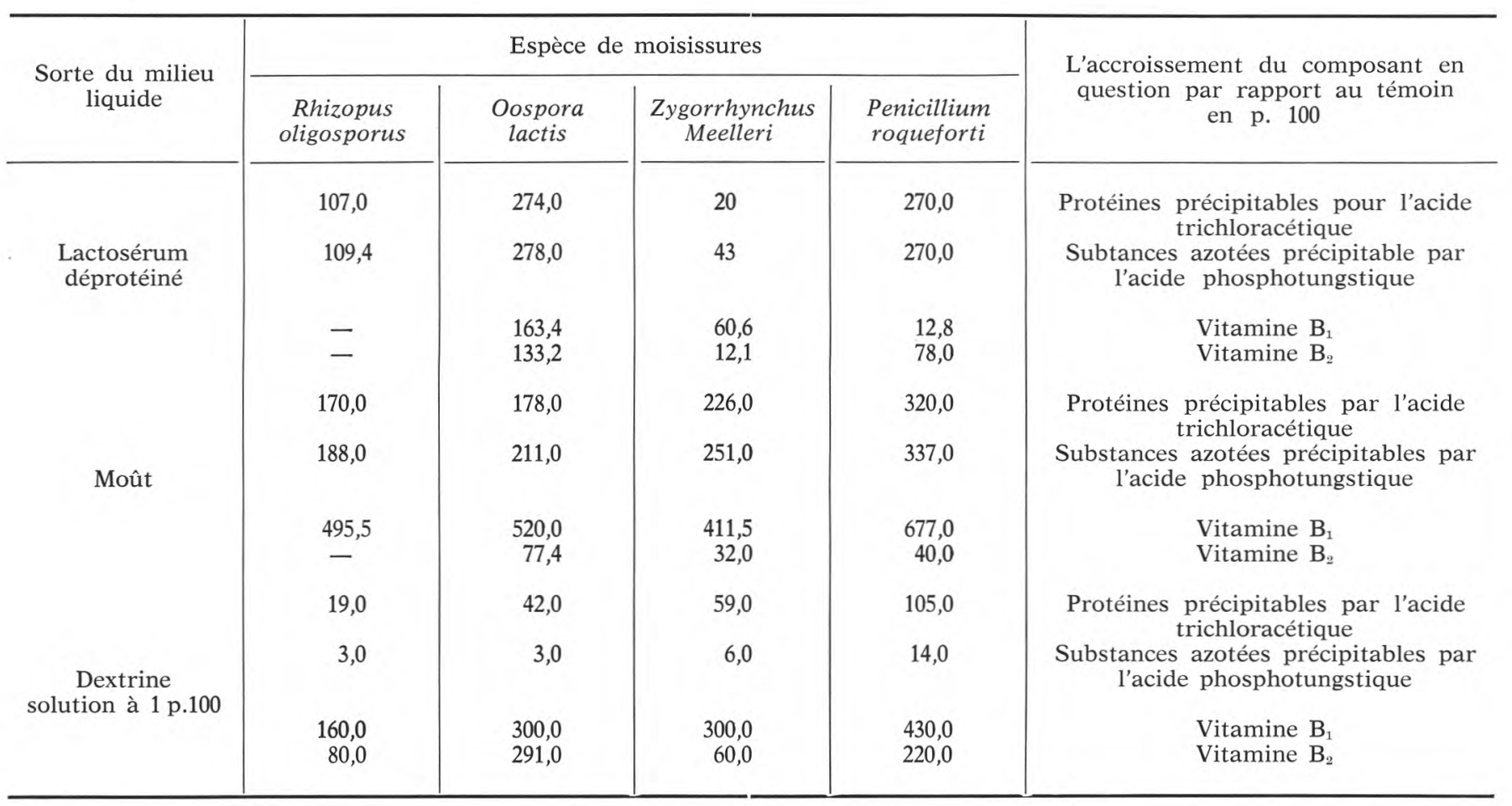


Des souches de Str. lactis, L. helveticus ou E. coli y étaient cultivées. Les germes $E$. coli se distinguaient par leur teneur en protéines élevée [11]. Dans la plupart des cas, la multiplication de la biomasse bactérienne s'effectuait en deux phases. D'abord, c'était le Str. lactis qui se multipliait à la température de $28^{\circ} \mathrm{C}$, puis $L$. helveticus à $45^{\circ} \mathrm{C}$. La souche d'E. coli se multipliait en une seule phase, à $37^{\circ} \mathrm{C}$. La multiplication de la biomasse bactérienne durait $60 \mathrm{~h}$, accompagnée d'une agitation fréquente et, de temps en temps, de la neutralisation, par $\mathrm{CaO}$, de l'acide lactique accumulé ou bien à l'aide d'eau ammoniacale à 5 p. 100. Dans quelques essais, outre le lactosérum enrichi de la biomasse bactérienne, le milieu était additionné de la biomasse de la levure $S$. fragilis, qu'on avait cultivée sur le lactosérum dans des conditions aérobies [12]. En deux cas, on y ajoutait encore 1'hydrolysat acide de kératine, précédemment neutralisé.

A ce substrat enrichi de la biomasse bactérienne, et quelquefois de la biomasse de levure, on ajoutait du son de froment stérilisé (50-70 g/l de lactosérum) et des pommes de terre étuvées et broyées, en même quantité que le lactosérum (poids pour poids).

Le substrat composé de la sorte était ensemencé avec la culture de moisissure, obtenue précédemment sur lactosérum dans des bô̂tes de Roux.

Dans quelques essais, le lactosérum enrichi de la masse bactérienne était remplacé par du flegme (1), obtenu par centrifugation des cellules de levure Saccharomyces fragilis, cultivées sur lactosérum et enrichi de combinaisons d'azote et de phosphore.

Le milieu ainsi préparé, ayant la consistance pâteuse, était placé en couches minces dans un local aéré, à la température de 24-26 $\mathrm{C}$. La culture des moisissures durait $84 \mathrm{~h}$, la masse entière étant agitée chaque fois après l'accroissement du mycélium. La culture terminée, on faisait passer le tout dans un moulin spécial, et on le séchait à $40^{\circ} \mathrm{C}$ pendant $24 \mathrm{~h}$, puis à $80^{\circ} \mathrm{C}$. Après séchage, la préparation d'amidon, de protéines et de vitamines avait l'apparence de grosse farine et se distinguait par son odeur agréable de pain, de champignon et de bouillon. En même temps, on séchait de même manière une portion du milieu sans y cultiver la moisissure, pour servir de témoin. Il contenait des protéines natives du lactosérum, des pommes de terre, ainsi que celles de la biomasse bactérienne accumulée. Cette préparation avait une odeur âpre et acide.

\section{b) Méthodes}

Outre les déterminations faites dans les cultures liquides, que nous avons décrites dans la première partie de notre exposé, dans les préparations d'amidon, de protéines et de vitamines on a déter-

(1) Résidu, ou bien liquide surnageant, obtenu par centrifugation de la culture de levure. 
miné aussi la cellulose, les cendres, la teneur en amidon et en eau, ainsi que l'acidité potentielle, volatile et active $(\mathrm{pH})$. Dans trois échantillons de la préparation, dont la technologie de fabrication était semblable, la valeur brute de protéine (Gross Protein Value) a été déterminée. Des essais de nutrition étaient alors réalisés avec des poulets de race "Leghorn".

\section{III. - RESULTATS}

Des données qui ont été présentées dans le tableau 2 on peut conclure que les quatre espèces de moisissures possédaient l'aptitude à synthétiser des protéines et des vitamines sur le milieu enrichi de la biomasse bactérienne, qui contenait $2-5$ p. 100 de lactose et $15-18$ p. 100 d'amidon de pommes de terre.

Parmi les quatre moisissures étudiées, c'étaient $O$. lactis et $Z$. Meelleri qui ont montré l'accroissement le plus élevé de protéines sur ce milieu, tandis que $P$. roquefort $i$ donnait l'augmentation la plus faible.

L'utilisation des composés anorganiques d'azote a été la plus élevée chez $R$. oligosporus environ $90 \mathrm{p} .100$, en comparaison avec 58 p. 100 chez $O$. lactis, 50 p. 100 chez Z. Meelleri et 46 p. 100 chez $P$. roqueforti. Il n'est pas exclu, que dans le cas de $R$. oligosporus, la synthèse des protéines peut être limitée par l'utilisation intense de la source d'azote dans le milieu. De même que dans la synthèse des protéines, la moisissure $O$. lactis a montré la plus grande aptitude à synthétiser les vitamines $\mathrm{B}_{1}$ et $\mathrm{B}_{2}$ ensemble. En comparaison avec le milieu enrichi de la biomasse bactérienne, et le même milieu additionné de pommes de terre étuvées, l'augmentation de la teneur en vitamines a atteint 210 p. 100 dans la culture de $O$. lactis, 170 p. 100 dans celle de P. roqueforti, 140 p. 100 chez $R$. oligosporus et 125 p. 100 chez $Z$. Meelleri.

Les résultats positifs que nous avons obtenus dans la synthèse des protéines et des vitamines par les organismes étudiés nous ont encouragé à continuer nos recherches sur l'intensification de ce procédé.

Comme il ressort du tableau 2, la moisissure de $P$. roqueforti a montré, en comparaison avec les autres, une aptitude assez faible à synthétiser des protéines sur le milieu au lactosérum concentré deux fois. D'autre part, son aptitude élevée à synthétiser des protéines sur le lactosérum déprotéiné, qui montait jusqu'à 270 p. 100 et, sur le moût à 320 p. 100 , nous a décidé à poursuivre la synthèse des protéines par $P$. roqueforti sur le lactosérum non concentré. Comme on le voit au tableau 3, sur milieu avec lactosérum non concentré, l'aptitude à synthétiser des protéines non seulement ne le cédait pas à celle de $O$. lactis ou de Z. Meelleri sur milieu avec lactosérum deux fois concentré, mais encore les surpassait (cf. tab. 2 et 3). Les données du tableau 3 montrent que la teneur en protéines précipi- 
TABLEAU 2

Comparaison de l'aptitude de biosynthèse de protéines et vitamines entre quatre espèces de moisissures (en lactosérum deux fois condensé)

\begin{tabular}{|c|c|c|c|c|c|c|c|c|}
\hline \multirow{3}{*}{$\begin{array}{l}\text { Composants analysés en p. } 100 \text { et } \\
\text { autres renseignements } \\
\text { caractéristiques }\end{array}$} & \multicolumn{8}{|c|}{ Espèce de moisissures } \\
\hline & \multicolumn{2}{|c|}{ Rhizopus oligosporus } & \multicolumn{2}{|c|}{ Oospora lactis } & \multicolumn{2}{|c|}{$\begin{array}{l}\text { Zygorrhynchus } \\
\text { Meelleri }\end{array}$} & \multicolumn{2}{|c|}{$\begin{array}{l}\text { Penicillium } \\
\text { roqueforti }\end{array}$} \\
\hline & 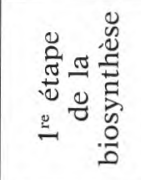 & 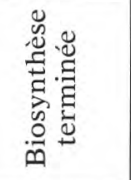 & 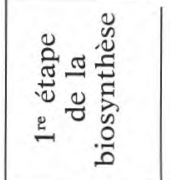 & 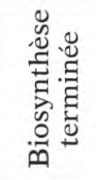 & 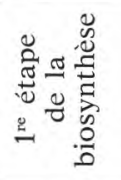 & 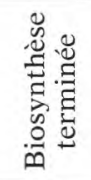 & 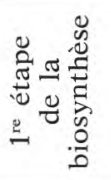 & 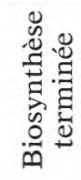 \\
\hline 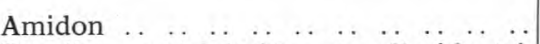 & 4,65 & 1,2 & 4,8 & 1,4 & 5,4 & 1,3 & 5,05 & 1,20 \\
\hline $\begin{array}{l}\text { Protéines précipitables par l'acide tri- } \\
\text { chloroacétique ..... . . . . . . . . . . } \\
\text { Substances azotées précipitables par }\end{array}$ & 9,2 & 13,7 & 9,9 & 15,6 & 7,35 & 14,2 & 6,6 & 9,7 \\
\hline l'acide phosphotungstique ... & 9,7 & 14,3 & 10,8 & 16,2 & 9,00 & 15,5 & 6,95 & 10,5 \\
\hline 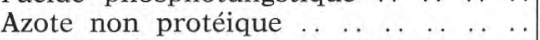 & 0,98 & 0,11 & 1,53 & 0,63 & 1,65 & 0,82 & 1,16 & 0,63 \\
\hline 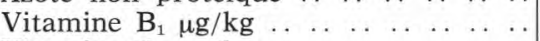 & 1660 & 3000 & 1000 & 1600 & 2000 & 3000 & 2100 & 3200 \\
\hline 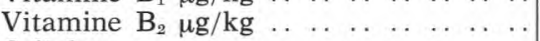 & 1800 & 2870 & 2140 & 5350 & 1430 & 2500 & 1640 & 3570 \\
\hline $\begin{array}{lllllllllll}\text { Cellulose } & \ldots & \ldots & \ldots & \ldots & \ldots & \ldots & \ldots & \ldots & \ldots & \ldots\end{array}$ & 5,8 & 7,1 & 4,2 & 5,9 & 5,3 & 6,1 & 4,0 & 5,55 \\
\hline $\begin{array}{lllllllllll}\text { Cendres } & \ldots & \ldots & \ldots & \ldots & \ldots & \ldots & \ldots & \ldots & \ldots & \ldots\end{array}$ & 7,2 & 8,9 & 7,3 & 9,5 & 5,8 & 8,2 & 6,9 & 9,1 \\
\hline $\begin{array}{lllllllllll}\text { Sucres réducteurs } & \ldots & \ldots & \ldots & \ldots & \ldots & \ldots & \ldots\end{array}$ & 2,72 & 0,72 & 5,66 & 1,30 & 3,80 & 0,80 & 6,53 & 1,70 \\
\hline 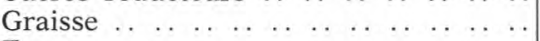 & & & NON DETERMINEE & & & & & \\
\hline $\begin{array}{lllllllllllll}\text { Eau } & \ldots & \ldots & \ldots & \ldots & \ldots & \ldots & \ldots & \ldots & \ldots & \ldots & \ldots & \ldots\end{array}$ & 3,8 & 5,25 & 3,8 & 5,6 & 6,0 & 6,5 & 3,4 & 5,3 \\
\hline 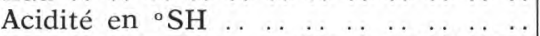 & 28 & 18 & 28 & 21 & 31 & 21 & 30 & 26 \\
\hline Acidité volatile en p. 100 de $\mathrm{CH}^{3} \mathrm{COOH}$ & 0,08 & 0,13 & 0,08 & 0,14 & 0,07 & 0,14 & 0,05 & 0,16 \\
\hline $\begin{array}{lllllllllllll}\mathrm{pH} & \ldots & \ldots & \ldots & \ldots & \ldots & \ldots & \ldots & \ldots & \ldots & \ldots & \ldots & \ldots\end{array}$ & 4,40 & 5,6 & 4,9 & 5,4 & 4,3 & 5,5 & 4,4 & 5,3 \\
\hline
\end{tabular}


TABLEAU 3

Caractéristiques de la préparation obtenue à partir du lactosérum non condensé (Moisissure utilisée : P. roqueforti)

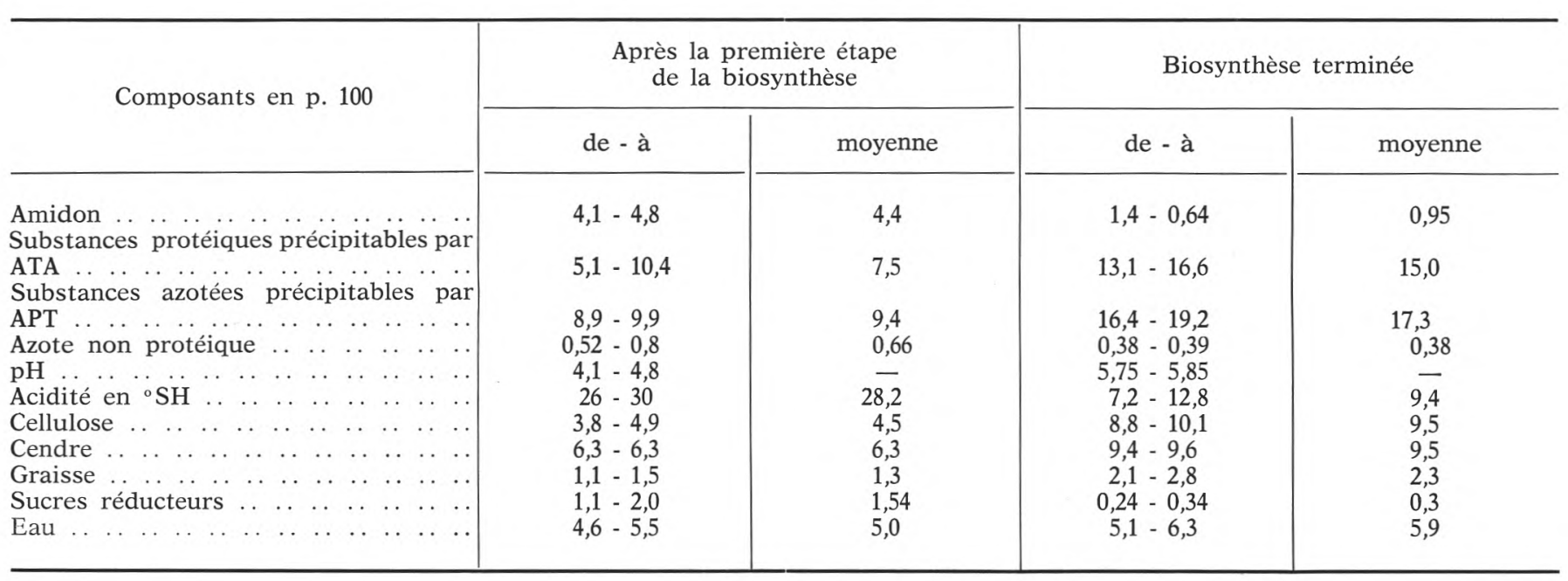


tables par ATA s'établissait entre 13 et 16,6 p. 100 et celle en substances azotées précipitables par APT, entre 16,4 - 19,2 p. 100. Ainsi, dans l'essai préliminaire, la concentration probablement élevée du lactose dans le milieu n'influençait pas le développement de $P$. roqueforti d'une manière favorable. En considérant le fait que $P$. roqueforti montre une tolérance beaucoup plus élevée aux changements de température, aux conditions d'aération et de concentration du sel, que les autres moisissures, l'utilisation de cette espèce pour la fabrication industrielle d'une préparation composée d'amidon de protéines et de vitamines paraît plus raisonnable. Au cours de l'expérimentation, on a observé l'aptitude à synthétiser les protéines de $Z$. Meelleri et de $P$. roqueforti sur un milieu où le lactosérum était remplacé par du flegme provenant de la fabrication de la levure Saccharomyces fragilis sur le lactosérum [12]. Des données du tableau 4, il est évident que l'aptitude à synthétiser des protéines sur le milieu avec du flegme de levure était minime, bien que ce milieu contînt tous les autres composants excepté le lactose et les petites quantités de protéines du lactosérum. L'addition au milieu de 50 p. 100 de lactosérum et 50 p. 100 de flegme de levure ne faisait améliorer que bien peu les résultats, tandis que celle de 50 p. 100 de lactosérum et de 50 p. 100 de la biomasse multipliée de levure sur lactosérum donnait des résultats proportionnellement inférieurs. Dans le dernier cas, la levure ajoutée inhibait le développement de la moisissure d'une manière apparente, et, en conséquence, la continuation de la synthèse des protéines. Cette série d'essais met en relief le rôle important des mono et disaccharides dans le processus de la biosynthèse des protéines par des moisissures, comme facteurs énergétiques indispensables.

Le niveau élevé des protéines n'a été constaté que dans la préparation où, la biosynthèse des bactéries et des moisissures étant accomplie sur le milieu avec le lactosérum et l'amidon de pommes de terre, 40 p. 100 de biomasse de levure multipliée avait été ajoutée (tab. 4). Il semble que cette tendance à utiliser la biomasse de levure en forme de lait de levure pour enrichir additionnellement en protéines la préparation d'amidon, de protéines et de vitamines, peut être plus économique que le séchage du lait de levure. Dans le cas de fabrication en masse de cette préparation, l'économie du lactosérum dans de grandes laiteries deviendrait effective.

Les tableaux 5 et 6 présentent l'aptitude, à la biosynthèse des protéines, de la moisissures $Z$. Meelleri sur milieu contenant du lactosérum deux fois concentré avec et sans addition d'hydrolysat acide de kératine provenant des cornes et des sabots. Comme il s'ensuit des tableaux 5 et 6 , l'addition de 5 p. 100 d'hydrolysat de kératine au milieu, stimule d'une manière apparente la biosynthèse des protéines. La teneur en protéines précipitables par ATA du milieu non additionné d'hydrolysat oscillait entre 14,2 et 15,7 p. 100, moyenne 15 p. 100 , et celle en substances azotées précipitables par 
TABLEAU 4

Caractéristiques de la préparation obtenue à partir du flegme de levure et du lactosérum additionné à la biomasse de levure (Moisissure : P. roqueforti ou Z. Meelleri)

\begin{tabular}{|c|c|c|c|c|c|c|c|c|}
\hline \multirow[b]{2}{*}{$\begin{array}{l}\text { Composants analysés en p. } 100 \\
\text { et autres renseignements } \\
\text { caractéristiques }\end{array}$} & \multicolumn{2}{|c|}{$\begin{array}{l}\text { A partir du flegme } \\
\text { de la levure }\end{array}$} & \multicolumn{2}{|c|}{$\begin{array}{l}50 \text { p. } 100 \text { de lactosérum } \\
\text { et } 50 \text { p. } 100 \\
\text { de flegme de levure }\end{array}$} & \multicolumn{2}{|c|}{$\begin{array}{l}50 \text { p. } 100 \text { de lactosérum } \\
\text { de } 50 \text { p. } 100 \text { de } \\
\text { biomasse de levure }\end{array}$} & \multicolumn{2}{|c|}{$\begin{array}{l}\text { Lactosérum }+40 \mathrm{p} .100 \\
\text { de biomasse de levure } \\
\text { après biosynthèse }\end{array}$} \\
\hline & 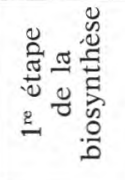 & 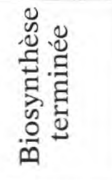 & 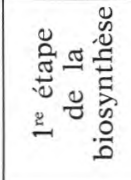 & 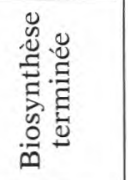 & 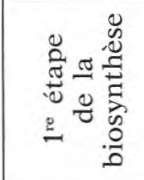 & 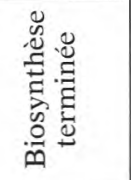 & 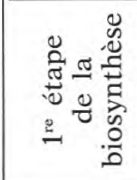 & 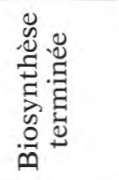 \\
\hline Amidon ... . & 4,5 & 1,1 & 3,5 & 1,6 & 3,8 & 1,95 & 4,12 & 1,2 \\
\hline $\begin{array}{l}\text { Protéines précipitables par l'acide tri- } \\
\text { chloracétique ... } \\
\text { Substances azotées précipitables par }\end{array}$ & 7,4 & 9,3 & 5,93 & 9,9 & 5,9 & 11,9 & 10,6 & 15,9 \\
\hline l'acide phosphotungstique ... . . ... .. & 8,2 & 9,4 & 8,1 & 11,2 & 8,6 & 17,5 & 9,4 & 19,2 \\
\hline Azote non protéique $\ldots \ldots \ldots \ldots \ldots$ & 0,53 & 0,32 & 0,57 & 0,61 & 0,56 & 0,46 & 0,8 & 0,3 \\
\hline $\begin{array}{lllllllll}\text { Cellulose } & \ldots & \ldots & \ldots & \ldots & \ldots & \ldots & \ldots & \ldots\end{array}$ & 3,8 & 8,7 & 1,2 & 12,0 & 4,2 & 10,1 & 4,5 & 9,5 \\
\hline $\begin{array}{llllllllll} & \ldots & \ldots & \ldots & \ldots & \ldots & \ldots & \ldots & \ldots & \ldots\end{array}$ & 6,4 & 8,3 & 5,8 & 9,1 & 7,9 & 8,1 & 5,6 & 8,2 \\
\hline 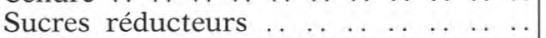 & 0,21 & nul & 2,3 & 0,19 & 1,1 & 0,33 & 2,3 & 0,18 \\
\hline Graisse $\ldots \ldots \ldots \ldots \ldots \ldots$ & 1,4 & 2,4 & 1,4 & 3,3 & 1,0 & 1,9 & 1,3 & 1,9 \\
\hline 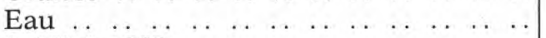 & 5,9 & 3,2 & 8,0 & 4,0 & 6,3 & 4,1 & 5,6 & 7,4 \\
\hline $\begin{array}{llllllllll} & \text { Acidité }{ }^{\circ} \mathrm{SH} & \ldots & \ldots & \ldots & \ldots & \ldots & \ldots & \ldots & \ldots\end{array}$ & 28,2 & 35,0 & 31,0 & 19,0 & 8,8 & 30,0 & 27,0 & 9,2 \\
\hline Acidité volatile en p. 100 de $\mathrm{CH}^{3} \mathrm{COOH}$ & 0,11 & 0,29 & 0,1 & 0,17 & 0,23 & 0,52 & 0,15 & 0,31 \\
\hline $\begin{array}{llllllllllllll}\mathrm{pH} & \ldots & \ldots & \ldots & \ldots & \ldots & \ldots & \ldots & \ldots & \ldots & \ldots & \ldots & \ldots\end{array}$ & 4,5 & 4,0 & 4,1 & 5,0 & 6,0 & 4,1 & 4,6 & 5,6 \\
\hline
\end{tabular}


TABLEAU 5

Caractéristiques de la préparation obtenue à partir du lactosérum condensé deux fois (Moisissure utilisée : Z. Meelleri)

\begin{tabular}{|c|c|c|c|c|}
\hline \multirow{2}{*}{ Composants en p. 100} & \multicolumn{2}{|c|}{$\begin{array}{l}\text { Après la première étape } \\
\text { de la biosynthèse }\end{array}$} & \multicolumn{2}{|c|}{ Biosynthèse terminée } \\
\hline & de - à & moyenne & de - à & moyenne \\
\hline 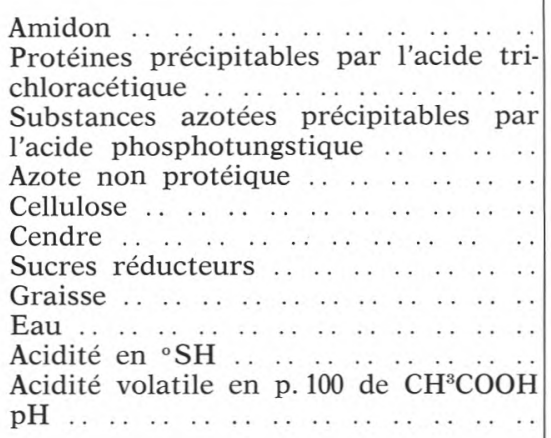 & $\begin{aligned} 4,5 & -7,3 \\
8,0 & -8,6 \\
7,3 & -8,7 \\
0,59 & -0,98 \\
3,9 & -4,8 \\
6,6 & -7,2 \\
3,55 & -3,84 \\
1,0 & -1,1 \\
4,6 & -6,1 \\
31 & -38 \\
0,075 & -0,11 \\
4,1 & -4,3\end{aligned}$ & $\begin{array}{l}5,6 \\
8,2 \\
8,4 \\
0,81 \\
4,2 \\
7,0 \\
3,7 \\
1,1 \\
5,6 \\
34 \\
0,09\end{array}$ & $\begin{aligned} 1,0 & -1,4 \\
14,2 & -15,7 \\
15,2 & -17,3 \\
0,45 & -0,68 \\
5,2 & -6,2 \\
9,9 & -10,7 \\
0,78 & -1,24 \\
2,0 & -2,3 \\
3,2 & -6,5 \\
24 & -31 \\
0,14 & -0,25 \\
4,8 & -5,2\end{aligned}$ & $\begin{array}{c}1,1 \\
\\
15,0 \\
\\
16,5 \\
0,57 \\
5,8 \\
10,3 \\
0,94 \\
2,1 \\
5,0 \\
28 \\
0,19\end{array}$ \\
\hline
\end{tabular}


TABLEAU 6

Caractéristiques de la préparation obtenue à partir du lactosérum condensé deux fois, additionné de l'hydrolysat acide de kératine (Moisissure utilisée : Z. Meelleri)

\begin{tabular}{|c|c|c|c|c|}
\hline \multirow{2}{*}{ Composants en p. 100} & \multicolumn{2}{|c|}{$\begin{array}{l}\text { Après la première étape } \\
\text { de la biosynthèse }\end{array}$} & \multicolumn{2}{|c|}{ Biosynthèse terminée } \\
\hline & de - à & moyenne & de - à & moyenne \\
\hline 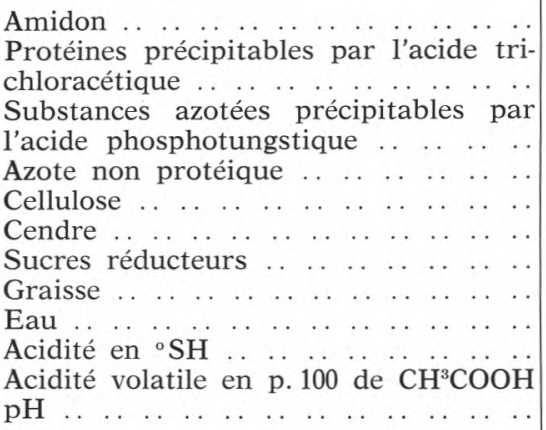 & $\begin{aligned} 5,0 & -5,6 \\
10,3 & -10,7 \\
10,6 & -10,7 \\
0,55 & -1,5 \\
4,3 & -4,9 \\
10,1 & -10,3 \\
3,7 & -3,9 \\
0,9 & -1,2 \\
5,5 & -5,8 \\
33 & -38 \\
0,07 & -0,08 \\
4,1 & -4,5\end{aligned}$ & $\begin{array}{c}5,3 \\
10,5 \\
10,6 \\
1,0 \\
4,6 \\
10,2 \\
3,8 \\
1,05 \\
5,6 \\
35 \\
0,07\end{array}$ & $\begin{aligned} 1,2 & -1,2 \\
16,7 & -20,2 \\
19,5 & -23,6 \\
0,52 & -1,7 \\
7,8 & -8,0 \\
13,1 & -14,3 \\
0,4 & -1,0 \\
1,9 & -2,2 \\
3,1 & -3,8 \\
31 & -33 \\
0,22 & -0,25 \\
4,8 & -5,4\end{aligned}$ & $\begin{array}{r}1,2 \\
18,5 \\
21,5 \\
1,1 \\
7,9 \\
13,7 \\
0,7 \\
2,0 \\
3,4 \\
27 \\
0,24\end{array}$ \\
\hline
\end{tabular}


APT variait de $15,2-17,3$ p. 100 , moyenne 16,3 p. 100 , tandis que dans le milieu additionné d'hydrolysat la teneur en protéines était de $16,7-20,2$ p. 100 , moyenne 18,5 p. 100 , et celle en substances azotées 19,5 - 20,6 p. 100 , moyenne 20,5 p. 100 . Il faudrait encore remplacer la neutralisation de l'hydrolysat avec le carbonate de sodium par celle avec l'oxyde de calcium ou avec l'hydroxide de barium, comme on l'a fait dernièrement. Au cours de la neutralisation avec du carbonate de sodium, une grande quantité de sels solubles de sodium pénétrait dans la solution pour augmenter sensiblement la teneur en cendre du produit fini.

Parmi les autres changements favorables qui se sont produits au cours de la biosynthèse des protéines sur les milieux en question, il faut mentionner l'augmentation du $\mathrm{pH}$ du milieu. Dans la plupart des cas, la valeur du $\mathrm{pH}$ de la préparation sèche variait de 4,3 à 4,5 après la première étape de la biosynthèse et de 5,3 à 5,5 et même davantage, une fois la biosynthèse accomplie. Ce n'est que dans des préparations produites avec du flegme de levure, la biomasse de levure étant ajoutée au milieu avant la biosynthèse par des moisissures, que le $\mathrm{pH}$ restait toujours bas. On n'a pas observé, au cours de cette expérimentation, de moisissure qui se distinguerait dans la neutralisation du milieu.

Au cours de la culture des moisissures, l'amidon de pommes de terre se transforme en dextrine de poids moléculaire varié. Immédiatement après l'addition de pommes de terre la teneur en amidon est montée à 15 - 18 p. 100 dans le milieu humide, et à $75-85$ p. 100 calculée en préparation sèche. Une hydrolyse de l'amidon était sans doute effectuée par des amylases de moisissures. La teneur moyenne en amidon de la préparation séchée n'aboutit qu'à $1-1,4$ p. 100. Déjà, après la première étape de la biosynthèse le milieu contenait des amylases, qui étaient probablement introduites par le son de froment. Après la dessiccation de ce millieu, immédiatement après l'addition des pommes de terre à la température de $40^{\circ} \mathrm{C}$ et puis à celle de $70-80^{\circ} \mathrm{C}$, la teneur en amidon variait de $5,6-3,8$ ! Le fait est à remarquer que pendant la culture des moisissures on n'avait jamais constaté une augmentation perceptible des sucres réducteurs, mais toujours leur réduction continuelle. C'est surtout le lactose, introduit dans le milieu avec le lactosérum, qui diminuait le plus. Par exemple dans la préparation terminée, qui était obtenue avec le flegme de levure, on n'a point constaté de sucres réducteurs. Après la première étape de la biosynthèse la teneur en sucres réducteurs n'atteignait que 0,21 p. 100 . On pourrait en conclure que diverses formes de dextrines se produisaient surtout au cours de l'hydrolyse de l'amidon, ainsi que de petites quantités de glucose qui subissait probablement une transformation immédiate à son tour.

$\mathrm{Au}$ cours de la culture des moisissures, les pertes en extrait sec sont montées à 20 p. 100 , et la réduction du lactose s'effectuait au premier rang. Il était difficile de constater quels étaient les autres 
composants du milieu qui étaient utilisés par les moisissures d'une manière la plus intense. L'abaissement apparent de l'acidité au cours de la synthèse par les moisissures indique la décomposition intense de l'acide lactique. Un accroissement insignifiant des graisses au cours de la biosynthèse des protéines par les moisissures ne peut pas être pris en considération.

Des expérimentations préliminaires de nutrition sur des rats ont démontré que les animaux mangeaient bien volontiers notre préparation composée d'amidon, de protéines et de vitamines. On n'a constaté aucun symptôme négatif extérieur, ni organique.

Des essais de nutrition sur des poulets de race "Leghorn " ont montré, que la valeur brute de protéine différait essentiellement dans les trois sortes de préparations. En comparaison avec le lait dégraissé en poudre et la caséine, il s'est présenté de la manière suivante :

\begin{tabular}{l|c|c|c}
\hline $\begin{array}{c}\text { Valeur brute } \\
\text { des protéines } \\
\text { en p. 100 }\end{array}$ & $\begin{array}{c}\text { Préparation } \\
\text { avec } \\
\text { du flegme } \\
\text { de levure } \\
\text { (tableau 4) }\end{array}$ & $\begin{array}{c}\text { Préparation } \\
\text { du P. roqueforti } \\
\text { avec } \\
\text { le lactosérum } \\
\text { non condensé } \\
\text { (tableau 3) }\end{array}$ & $\begin{array}{c}\text { Préparation avec } \\
\text { du lactosérum } \\
\text { deux fois condensé } \\
\text { additionnée } \\
\text { d'hydrolysat } \\
\text { de kératine } \\
\text { (tableau 6) }\end{array}$ \\
\hline $\begin{array}{c}\text { En comparaison avec } \\
\text { le lait dégraissé en } \\
\text { poudre ......... }\end{array}$ & 16 & 51 & 63 \\
$\begin{array}{c}\text { En comparaison avec } \\
\text { la caséine ....... }\end{array}$ & 15 & 47 & 57 \\
\hline
\end{tabular}

Comme il résulte de ces essais de nutrition ici présentés, la préparation qui était enrichie en acides aminés soufrés avec l'hydrolysat de kératine a montré la valeur biologique la plus haute. La même préparation contenait le niveau le plus élevé en protéines. Dans la préparation produite sur le lactosérum non condensé, dont la valeur brute des protéines était 51 p. 100 en rapport avec le lait en poudre et 47 p. 100 avec la caséine, un bas niveau des acides aminés soufrés a été constaté : environ $1,4 \mathrm{~g}-16 \mathrm{~g} \mathrm{~N}$ de la méthionine et environ $0,6 \mathrm{~g}-16 \mathrm{~g} \mathrm{~N}$ de la cistine-cistéine.

Une basse valeur brute de protéines a été constatée dans le mélange des préparations produites à partir : $1^{\circ} \mathrm{du}$ flegme de levure ; $2^{\circ}$ du mélange de 50 p. 100 du lactosérum et 50 p. 100 du flegme et $3^{\circ} 50$ p. 100 de lactosérum et 50 p. 100 de la biomasse de levure, bien que la teneur moyenne en protéines ne montrât pas une disproportion si grande -13 p. 100 contre 17 p. 100 . Les différences 
de la teneur en protéines étaient de 5 p. 100 , et celles de la valeur brute de protéines - de 35 p. 100. Le fait observé indiquerait que dans la préparation fabriquée à partir du flegme et avec une certaine addition de la biomasse de levure, des protéines provenant surtout des pommes de terre, et en petite quantité des levures, ne peuvent pas compenser les protéines du lactosérum et celles qui sont synthétisées par des bactéries et des moisissures.

\section{IV. - DISCUSSION}

Les résultats des expérimentations concernant la biosynthèse des protéines par des bactéries et des moisissures sur le milieu de lactosérum et de pommes de terre indiquent qu'on peut de telle manière augmenter considérablement la teneur en précieuses protéines des produits qui contiennent de grandes quantités d'amidon, tels que les pommes de terre, la farine de maïs et même le chou-navet, la betterave, etc. Par exemple, en remplaçant des pommes de terre par la farine de maïs, ont été obtenus des résultats analogues à ceux donnés par les pommes de terre.

Cette tendance de la biosynthèse des protéines peut avoir une grande importance économique, parce que, dans notre bilan de fourrages, nous avons un surplus d'amidon et en même temps un défaut apparent des protéines. Le procédé technologique en est relativement simple, et sa mise en œuvre sur un plan industriel n'exigera ni de grandes dépenses ni des arrangements spéciaux.

La valeur biologique des protéines contenues dans les préparations d'amidon, de protéines et de vitamines que nous avons mises au point, correspond approximativement à la valeur des protéines obtenues par Dluzewski [6], qui avait cultivé O. lactis sur des milieux artificiels (glucose, acides aminés, sels minéraux). D'après Dluzewski cette valeur montait à 40 p. 100 pour atteindre 80 p. 100 , le milieu artificiel étant enrichi en méthionine.

Les analyses que nous avons faites ont montré que les protéines de la préparation dont la valeur brute des protéines était de 51 p. 100 en comparaison avec le lait en poudre et 47 p. 100 en comparaison avec la caséine, avaient une composition en acides aminés indispensables tout à fait différente de celle de la caséine. Le défaut de certains acides aminés dans les protéines de la préparation montre, en comparaison avec la caséine, une grande divergence par la valeur déterminée de la protéine brute. En confrontant le pourcentage des acides aminés indispensables de la caséine rapporté par Alais [2] avec celui de mêmes acides aminés que nous avons déterminés dans les protéines de notre préparation, leur défaut dans cette dernière se présente de la manière suivante : 


\begin{tabular}{|c|c|c|c|c|}
\hline \multirow{2}{*}{$\begin{array}{l}\text { Acides aminés } \\
\text { p. } 100\end{array}$} & \multirow{2}{*}{$\begin{array}{l}\text { Caséine } \\
\text { d'après } \\
\text { Alais [2] }\end{array}$} & \multirow{2}{*}{$\begin{array}{c}\text { Préparation } \\
\text { caractéristique } \\
\text { of. tableau } 3\end{array}$} & \multicolumn{2}{|c|}{$\begin{array}{l}\text { Divergence } \\
\text { en p. } 100\end{array}$} \\
\hline & & & moins & plus \\
\hline 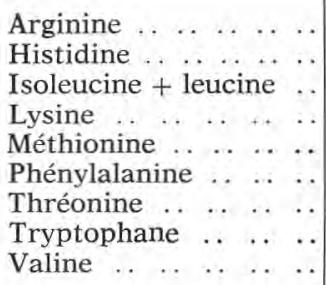 & $\begin{array}{r}4,4 \\
3,1 \\
15,3 \\
8,2 \\
2,8 \\
5,0 \\
4,4 \\
1,9 \\
7,2\end{array}$ & $\begin{array}{r}2,2-2,8 \\
3,8=4,0 \\
13,0=15,0 \\
6,1=6,8 \\
1,4=1,6 \\
5,0=5,2 \\
6,0=6,6 \\
0,6=0,7 \\
6,2=7,0\end{array}$ & $\begin{array}{l}50 \\
15 \\
25 \\
50\end{array}$ & 18 \\
\hline
\end{tabular}

Le plus grand défaut des acides aminés indispensables a été constaté pour le tryptophane -70 p. 100 , la méthionine -50 p. 100 , et l'arginine $-50 \mathrm{p} .100$. Pour la phénylalanine les valeurs sont semblables et pour la thréonine et l'histidine elles sont un peu plus élevées. Des acides aminés importants, la teneur en acide glutamique était aussi de 60 p. 100 plus basse que celle de la caséine.

Nos expérimentations seront continuées avec l'intention, d'une part, d'augmenter le rendement de la synthèse des protéines et d'autre part, d'enrichir la préparation obtenue en acides aminés limités, à l'aide de la biosynthèse, ou bien en les suppléant avec des produits de déchet, accessibles et peu coûteux, tels que les kératines, etc. L'utilisation de certaines souches d'E. coli pour la synthèse bactérienne, au lieu de Str. lactis et de L. helveticus, enrichirait sans doute la préparation en un acide aminé aussi déficitaire que le tryptophane $[5,11]$. De même, certaines souches de bactéries propioniques pourraient la suppléer en vitamine $B_{12}$. L'utilisation des autres espèces de moisissures, telles que Climacodon septentrionalis, Coriolus raporarius, Tricholoma fulvem, Tricholoma saponaceum et d'autres [1] qui se distinguent par l'aptitude d'accumulation du mycélium, avec une teneur en protéines de $25-40$ p. 100 , peut se montrer encore plus économique pour la biosynthèse des protéines. L'addition d'acides aminés synthétiques augmenterait, peut-être, la valeur biologique de la préparation. La biosynthèse des protéines a été intensifiée par l'hydrolyse préliminaire du lactosérum condensé par la papaïne, pour obtenir un accroissement des protéines de plus de 2 p. 100. Sur le milieu au lactosérum hydrolysé avec la papaïne, on a observé une synthèse plus élevée des protéines, aussi bien par des bactéries lactiques que par la moisissure $Z$. Meelleri.

Il n'est pas douteux que des différences d'accroissement des protéines dans la limite de 2 p. 100 ne résoud pas encore le problème de l'intensification de la synthèse. Ce fait indique pourtant qu'existent des possibilités réelles. 


\begin{tabular}{|c|c|c|c|c|c|c|}
\hline & \multicolumn{3}{|c|}{$\begin{array}{l}1^{\text {re }} \text { étape de la biosynthèse } \\
\text { (biosynthèse bactérienne) }\end{array}$} & \multicolumn{3}{|c|}{$\begin{array}{c}2^{\text {me }} \text { étape de la biosynthèse } \\
\text { (moisissure } Z \text {. Meelleri) }\end{array}$} \\
\hline & 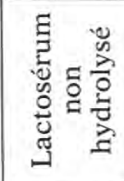 & 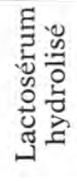 & 峁 & 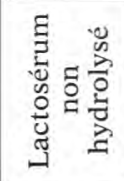 & 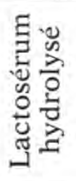 & 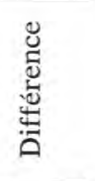 \\
\hline $\begin{array}{l}\text { Protéines précipitables } \\
\text { par ATA en p. } 100 \ldots\end{array}$ & 7,5 & 8,5 & 1,0 & 15,2 & 17,4 & 2,2 \\
\hline 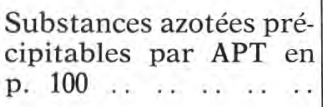 & 9,0 & 11,3 & 2,3 & 17,7 & 19,7 & 2,0 \\
\hline
\end{tabular}

La réduction des pertes d'extrait sec et de la durée de la biosynthèse exige, elle aussi, la continuation de nos études. Des résultats pleins de promesses ont été obtenus en réalisant un cycle de biosynthèse en trois phases :

1) Culture de la biomasse bactérienne sur un milieu liquide.

2) Culture de la moisissure en couche mince, additionnée de talc comme charge.

3) Culture finale des moisissures sur milieu additionné de pommes de terre.

\section{$R$ és u m é}

On a effectué la biosynthèse des protéines et des vitamines en deux étapes, par des bactéries et des moisissures, sur milieu avec lactosérum et pommes de terre. En première étape, la biomasse des bactéries Str. lactis, L. helveticus ou $E$. coli était multipliée sur le lactosérum condensé ; puis le même milieu était enrichi en amidon par addition de pommes de terre pour créer des conditions favorables à la continuation de la biosynthèse par les moisissures : Penicilium roqueforti, Oospora lactis, Zygorrhynchus Meelleri et Rhisopus oligosporus.

La biomasse bactérienne a été multipliée jusqu'au moment où la teneur en lactose du lactosérum était réduite jusqu'à 4 p. 100 . Les moisissures étaient cultivées pendant $84 \mathrm{~h}$, en agitant plusieurs fois la couche mince du milieu chaque fois qu'elle était recouverte de mycélium. La préparation obtenue était alors séchée.

Selon la sorte du milieu, le procédé de la culture et l'espèce de la moisissure utilisés, la teneur en protéines précipitables de la préparation sèche par l'acide trichloracétique variait de 14 à 20 p. 100, 
tandis que la teneur en substances azotées précipitables par l'acide phosphotungstique se situait entre 16,5 et 24 p. 100. Par son apparence, la préparation sèche ressemblait à de la grosse farine, et elle se distinguait par la saveur plaisante de pain, de champignons séchés ou de bouillon.

Des essais de nutrition faits sur des poulets de race "Leghorn » ont montré que la valeur brute de protéine avait abouti à 51 63 p. 100, en comparaison avec le lait en poudre dégraissée, et 47 - 57 p. 100 en comparaison avec la caséine.

\section{Su m m a ry}

Our attention has been drawn on the possibilites of whey to be used as medium for mold biosynthesis of proteins and vitmins. Under conditions of this country, the pototo may by chosen as an additonal component of the medium, in which such biosynthesis would take place.

In our experiments on protein and vitamin synthesis, the following mould species were used : Penicilium roqueforti WR-16, Oospora lactis-15, Zygorrhynchus Moelleri LECK-91 and Rhisopus Oligosporus CBS 33962.

At the first stage of our experiments, the said moulds were cultivated in Roux bottels on following media : 1) whey, 2) wort, 3) 1 p. 100 dextrin solution. These media were supplemented with 0,5 p. $100 \mathrm{NH}_{4} /{ }_{2} \mathrm{HPO}_{4}-0,5$ p. $100 \mathrm{~K}_{2} \mathrm{HPO}_{4}$ and 0,05 p. $100 \mathrm{MgSO}_{4} 7 \mathrm{H}_{2} \mathrm{O}$ which served as sources of mineral Nitrogen and microelements.

At the second stage, a starch-whey medium was prepared with addition of potatoes. The preparation of the medium and conditions of biosynthesis were as follows : whey, was used as stock material, it was twice condensed, or used without condensation. Abaut 15 p. 100 of corn chaff on bran and $\mathrm{KH}_{2} \mathrm{PO}_{4}, \mathrm{MgSO}_{4}$ and urea or $\mathrm{NH}_{4} /{ }_{2} \mathrm{HPO}$, were added to whey as nitrogen source. This prepared medium was acidified by bacterial fermentation, up to moment when fast all lactose had been fermented. Thus enriched with bacterial biomass, the medium was then supplemented with potatoes, previously cooked and pulped, at the ratio of 1-1. Thus composed substrate was inoculated with mould culture. When the growth had been completed, the product was dried. A starch-protein-vitamin fodder preparation was obtained, the appearence of which resembled to that of whole-meal. It was characterized by a pleasant smell and a taste of bread, dried mushrooms and broth. It contained abaut 20 p. 100 of protein, $3000 \mu \mathrm{g} / \mathrm{kg}$ of vitamin $\mathbf{B}_{1}, 5000 \mu \mathrm{g} / \mathrm{kg}$ of vitamin $\mathbf{B}_{2}$. The preparation showed gross protein value of 70 p. 100 , as compared to skim milk powder. When analysed on aminoacids composition, the low content of sulphuric aminoacids was found. To compensate this deficiency 2 p. 100 of keratine hydrolysate was added to the medium. 


\section{Références bibliographiques}

[1] Akademia Nauk Latwijskioj S.S.R. (1966). - Produkty Mikrobnogo Sinteza, Riga, p. 78.

[2] Alais (Ch.) (1961). - Science du Lait et Principes des Techniques laitières, Paris, p. 76.

[3] Anwar (A.) (1960). - Poultry Sci., 39, 1406.

[4] Anwar (A.) (1961). - Poultry Sci., 40, 1014.

[5] Biochemical Genetics and Protein Synthesis (1967). - PWN Warszawa, 59.

[6] Dluzewski (M.) (1965). - Zeszyty Problemowe Postepow Nauk Roln, 53, p. 135.

[7] Ellinger (G. M.) (1957). - Proc. Nutr. Soc., 17, 100.

[8] Mejbaum-Katzenellbogen (W.), Mochnacka (J.) (1968). - Kurs praktyczny z biochemii. Wyd. II, Warszawa.

[9] MülLler (Z) and Rozycka (B.) (1965). - Chimiczeskije i biologiczeskije preparaty w karmlenii ziwotnych "Kolos ", Moskwa.

[10] Nesterowa (E. A.) (1967). - Metody opredielenija witaminow w kormach, Moskwa.

[11] Rainbow (C.) and Rose (A. H.). - Biochemistry of Industrial Microorganisms, New-York, p. 47, 221.

[12] Surazynski (A.), Poznanski (S.), Andrzejewski (W.) (1968). - Milchwissenschaft, 23, s. 484.

[13] Thatcher (F. S.) (1954 - 1963). - Ann. Rev. Microbiol, p. 449, za RainBow (C.) and Rose (H.), Biochemistry of Industrial Micro-organism, NewYork, p. 46.

[14] U.S. Ministry for Agriculture Research Station, Pretoria (1968). Milchwissenschaft, 22, 11, p. 718. 